\title{
Telomeres and telomere dysfunctions
}

\section{Elena Georgiana Dobre, Sorina Dinescu ${ }^{\bowtie}$, Marieta Costache}

Department of Biochemistry and Molecular Biology, Faculty of Biology, University of Bucharest, 91-95 Splaiul Independentei, 050095 Bucharest, Romania

${ }^{\square}$ Correspondence to: Sorina Dinescu, Department of Biochemistry and Molecular Biology, Faculty of Biology, University of Bucharest, 91-95 Splaiul Independentei, 050095 Bucharest, Romania E-mail: sorina.dinescu@ bio.unibuc.ro

Received: 16 July 2018 / Revised: 18 February 2019 / Accepted: 20 February 2019 / Available online: 22 February 2019

\begin{abstract}
The length of telomeres is an important determinant of cell viability and phenotype. In stem cells, telomere shortening affects their self-renewal potential and compromises the regeneration of a variety of tissues. Telomeropathies, also known as telomeres diseases or telomeres syndromes, are a suggestive example in this context. These diseases are caused by mutations in genes coding for proteins involved in telomere maintenance and repair. Telomere attrition is also a source of genomic instability. Cells that display frayed telomeres and dysfunctional tumor suppressor genes, often activate telomere maintenance mechanisms, telomerase or alternative lengthening of telomeres, and become immortal. Carcinogenesis is initiated more easily in stem cells, because they exhibit low levels of telomerase. Thus, in response to mutations induced by telomere shortening and environmental exposure, stem cells can enhance telomerase activity to stabilize their genome, gaining unlimited proliferation capacity at the same time. In this paper, we reviewed the literature on telomere biology in order to understand the molecular underpinnings of telomere maintenance and its involvement in human diseases, especially age-associated diseases and cancer.
\end{abstract}

Keywords: telomere shortening, telomeropathies, genomic instability, telomere maintenance mechanisms, telomerase, alternative lengthening of telomeres, stem cells, carcinogenesis

\section{Introduction}

The existence of particular structures at the ends of the chromosomes was postulated around the 1930s by the independent observations of Hermann Muller and Barbara McClintock (Gall, 1995). Yet, the telomeres structure was first described four decades later by Elizabeth Blackburn and Joseph Gall. They sequenced the ribosomal DNA macromolecules from Tetrahymena thermophila and observed that the chromosome extremities consisted of 20-70 tandem repeats of the 5'TTGGGG-3 ' $/$ 3'-AACCCC-5 hexameric sequence (Blackburn and Gall, 1978). The observations on ciliate telomeres remain valid nowadays as the telomeres of almost all species of eukaryotes, including humans, consist of a variable number of nucleotide repeats and the G-rich strand always forms the 3' end of the chromosome (de Lange, 2004; McKnight and Shippen, 2004; O'Connor, 2008).

Excepting cancer cells and embryonic cells, human cells telomeres shorten with aging. When the telomere length falls below a critical threshold, senescence and apoptosis occur (Shay and Wright, 2010). Telomeres shortening is accelerated if mutations in the proteins involved in monitoring and maintaining telomeres occur.
Dysfunctions in telomere maintenance machinery have serious consequences on the stem cells compartment (Martinez and Blasco, 2017). Dyskeratosis congenita (DC), Hoyeraal-Hreidarsson syndrome (HHS), Revesz syndrome, Coats Plus syndrome, idiopathic pulmonary fibrosis (IPF), aplastic anemia, and liver fibrosis also known as telomeropathies, telomeres diseases or telomeres syndromes, are suggestive examples in this context (Martinez and Blasco, 2017). In these diseases, cell proliferation is disturbed, which results in premature aging of a variety of tissues (bone marrow, epithelia, skin) (Holohan et al, 2014).

Telomeres are also involved in the control of genomic integrity and play a crucial role in initiating carcinogenesis (Gunes and Rudolph, 2013). Genomic instability can be considered a result of telomere uncapping (Sfeir and deLange, 2012; Nera et al, 2015), loss of DNA damage checkpoints (Wright and Shay, 1992), defective processing and repair of telomeric DNA (Rai et al, 2010; Gunes and Rudolph, 2013), replicative stress (Sarni and Kerem, 2017) and abnormal levels of telomeric proteins (Nera et al, 2015). Dysfunctional telomeres lead to end-to-end fusions, chromosome breakage or aneuploidy, all these events resulting in genomic instability (Shay and Wright, 2010). 
In order to stabilize the genome, cells activate telomeres maintenance mechanisms (TMMs): i.e. telomerase or Alternative Lenghtening of Telomeres (ALT), and become capable of unlimited proliferation (De Vitis et al., 2018). Immortalization occurs more easily in stem cells, where telomerase is already active at a basal level (Gunes and Rudolph, 2013).

The possible mechanisms linking telomeres, telomeric proteins and human diseases will be described below in details.

\section{Telomeres and telomere maintenance}

The extremities of linear eukaryotic chromosomes possess a particular segment of repetitive sequences called telomeres, which form a "cap" at each end of the chromosomes. Human cell telomeres consist of tandem repeats of the nucleotide sequence 5'TTAGGG3 ' 3'AATCCC5'; these double-stranded structures have a length between 9 and $15 \mathrm{~kb}$ and end with a 3 'singlestranded-DNA overhang (O'Sullivan and Karlseder, 2010). This overhang invades the telomeric duplex and through complexation with specific proteins forms a lariat structure called T-loop, which contributes to the maintenance of the telomeres' protective cap (Fig. 1) (Sfeir, 2012).
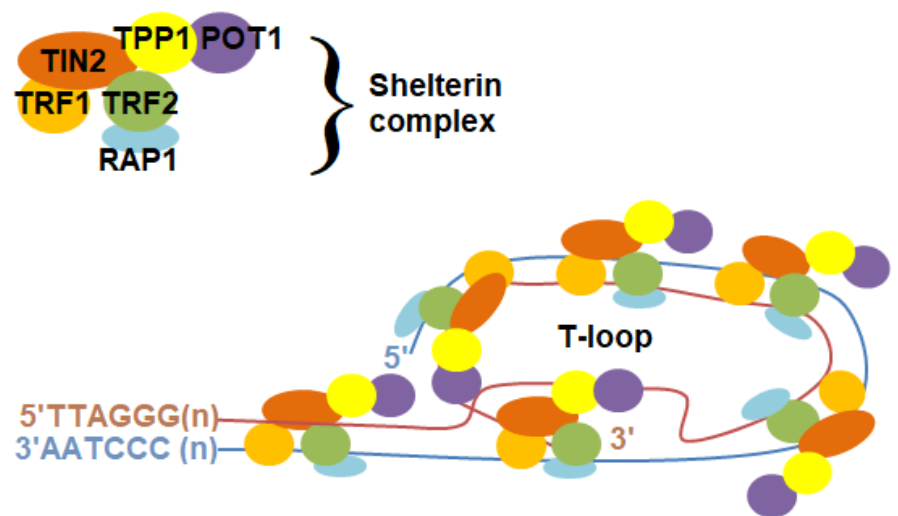

Fig. 1. Schematic representation of telomere structure.

Telomere length homeostasis is carefully controlled by numerous proteins, acting either independently or organized into complexes. Some of these proteins are found exclusively at telomeres, while others have subnuclear or subcellular localization (Campisi et al, 2001). By far, the most important proteins involved in telomere lenght maintenance are the six molecules organized in the shelterin complex (Figure 1) (Palm and de Lange, 2008). Telomeric Repeat-binding Factor 1 (TRF1) and Telomeric Repeat-binding Factor 2 (TRF2) bind duplex telomeric DNA (Broccoli et al, 1997; Palm and de Lange, 2008), whereas Protection Of Telomeres 1 (POT1) binds to single stranded DNA (Baumann et al, 2002; O'Sullivan and Karlseder, 2010). TRF1 assures correct telomere replication (Martinez, 2009), while TRF2 regulates telomeric DNA topology (Amiard, 2007) and assist the T-loop assembly, a lariat structure that protects telomeres against DNA Damage Repair (DDR) complex (Denchi and de Lange, 2007). The other proteins do not interact with telomeric DNA. TRFInteracting Nuclear protein 2 (TIN2) stabilizes the interaction between TRF1 and TRF2 (Ye and Donigian, 2004) and recruits Tripeptidyl-peptidase 1 (TPP), which interacts with POT1 (Takai et al, 2011). TPP1 and POT1 compete with telomerase for the 3 'overhang end. TPP1 interaction with telomerase enhances enzyme processivity, while increased loading of POT1 along the overhang blocks the interaction of telomerase with its substrate (O'Sullivan and Karlseder, 2010). In addition, Repressor and Activator Protein 1 (RAP1) does not bind directly to the repetitive sequences in the telomere structure and its presence in the Shelterin complex depends on interaction with TRF2 (Figure 1) (Li and Oestreich, 2000; Yang et al, 2005).

Members of the shelterin complex interact with a series of cofactors to induce the T-loop conformation assembly and to protect the terminal ends of the chromosomes. Proteins recruited at telomeres by shelterins include helicases, nucleases and proteins responsible for telomeric DNA replication and repair (Raynaud et al, 2008). Mutations in these accessory molecules have serious implications for aging and health, causing telomere diseases (Martinez and Blasco, 2017).

Replication of telomere occurs after replication of the entire chromosome and is facilitated by telomeric proteins (Raghuraman et al., 2001). Conventional polymerases do not have the ability to replicate the entire parental DNA on the lagging strand, therefore, human telomeres progressively shorten along successive cell divisions, and each round of division results in the loss of 50-200 base pairs (Huffman et al., 2000). Once telomeres reached a critical length, they are recognized by the machinery involved in DDR, which will impose cell cycle arrest or apoptosis. The entry of cells into the replicative senescent state is a mechanism designed to ensure genomic stability and prevent malignant transformation of normal cells (Shay and Wright, 2010).

Over the time, the study of epigenetic changes of telomeric chromatin revealed that epigenetic regulation is another key factor that controls telomeric length and function. The telomeres are highly compacted structures, normally endowed with the epigenetic markers of constitutive heterocromatin: trimethylation of histone $\mathrm{H} 3$ at lysine 9 (H3K9me3) and histone $\mathrm{H} 4$ at lysine 20 (H4K20me3), hypoacetylation of $\mathrm{H} 3$ and $\mathrm{H} 4$ and subtelomeric DNA hypermethylation (Blasco, 2007).

Changes in the epigenetic pattern of telomeric chromain trigger abnormal events in living organisms, for instance, diminished histone methylation leads to aberrant elongation of telomeres (Garcia-Cao et al, 2004; Benetti et al, 2007b), while decreased telomeric and subtelomeric DNA methylation leads to telomeric fusions (Gonzalo et $a l$, 2006). These observations are of particular importance in the context of neoplasms, where low methylation 
levels of chromatine have been reported, and where TMMs-mediated telomere elongation confers infinite replicative potential to cancer cells (Blasco, 2007). Regarding aging-associated conditions, it is supposed that the existence of extremely short telomeres leads to epigenetic changes that weaken telomeric silencing. Besides hypomethylation, extremely short telomere are characterized by the hyperacetylation of telomeric and subtelomeric chromatin, which is a feature of the transcriptionally active chromatin (Benetti et al, 2007a). These observations are in line with the telomeres position effect (TPE), where reversible silencing of the genes located near telomeres relies on telomeric elongation (Blasco, 2007).

Moreover, the lifestyle choices can have a significant influence on the rate of telomere shortening. Healthy diets including vegetables, vegetable oils, nuts and fish are rich in biological compounds with antioxidant and anti-inflammatory action and promote the stability of telomeres (Marin et al, 2012; Crous-Bou et al, 2014). In contrast, diets based on red meat and sweetened carbonated beverages (Lee et al, 2015; Leung et al, 2008), along with stress exposure (Epel et al, 2004), smoking and a sedentary behaviour (Valdes et al, 2005) have been shown to accelerate telomere shortening, leading to modification in telomeric and subtelomeric chromatine that promote the development of age-related conditions (Blasco, 2007).

\section{Telomerase}

Telomerase is a specialized polymerase capable of synthesizing TTAGGG repeat sequences at the 3 'end of telomeric DNA (Greider and Blackburn, 1985). The discovery of this mechanism is one of the most important advances in the history of modern molecular biology, for which Greider and Blackburn were awarded Nobel Prize in 2009.

Human telomerase has two essential components: a catalytic subunit, hTERT, with reverse transcriptase activity and a RNA molecule (hTR or hTERC). Telomerase uses its own RNA, which has a 11 bp sequence complementary to repetitive motifs, as a template for telomeric DNA synthesis (TTAGGG)n (Brown et al, 2014). Dyskerin (DKC), NHP2, NOP10 and GAR1 are also part of the telomerase ribonucleoproteic complex (Egan and Collins, 2010) (Fig. 2). Mutations in telomerase core components cause diseases known as telomeres dysorders (Holohan et al, 2014; Martinez and Blasco, 2017).

The inactive telomerase complex is assembled in nucleus, in the Cajal bodies, and these corpuscles are then transported near the telomere by the Telomerase Cajal Body Protein 1 (TCAB1) (Venteicher et al, 2009). The ATP-ases pontin and reptine interact with the inactive complex, in order to activate and initiate the synthesis of repeating units at the 3 'end of the telomeric DNA (Venteicher et al, 2008).
In humans, telomerase is well expressed in the early stages of embryogenesis, but the gene encoding the hTERT subunit is repressed, thus, the enzymatic activity of telomerase is diminished considerably. Telomerase remains activated in male germ cells and in several somatic cell types, such as activated lymphocytes and stem cells from tissues with increased rates of regeneration (Wright et al, 1996).

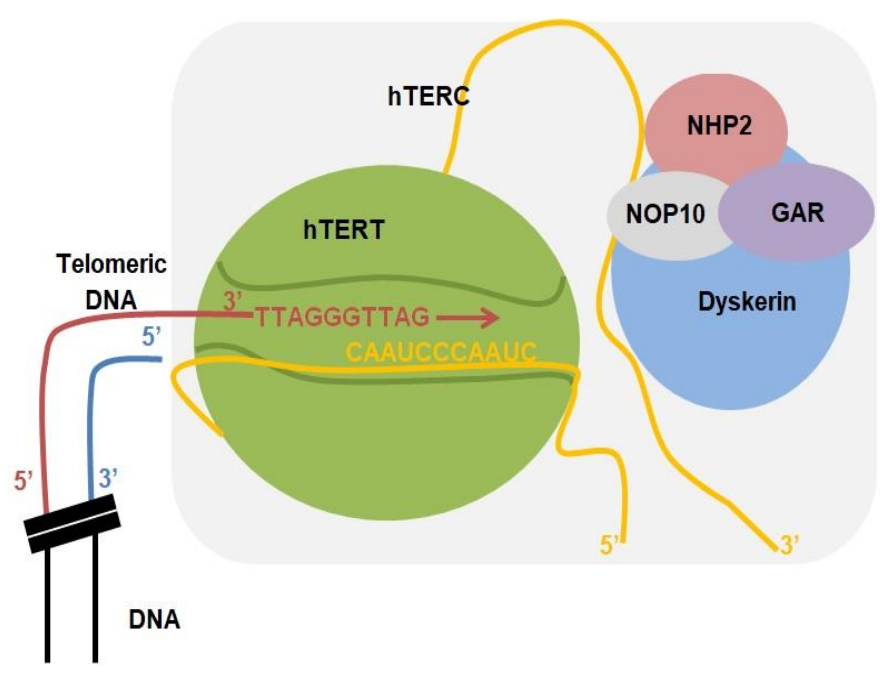

Fig. 2. Telomerase core components and the mechanism of telomere maintenance.

Due to its activity, telomerase counteracts telomere shortening that occurs during DNA replication. In normal somatic cells, telomerase is in an almost inactive state, which allows the telomeres to be shortened with each replication (Wright et al, 1996). Instead, telomerase is active in about $90 \%$ of the tumor cells studied, where its activity cancels out telomere shortening effects and gives immortality to cell clones (Stewart et al, 2002; De Vitis et al, 2018). Maintaining telomere is an essential feature of tumor cells capable of continuous proliferation, so tumor cells in which telomerase is not active use another TMM to ensure immortality: ALT (Cesare and Reddel, 2010).

Studies of Artandi and De Pihno (2000) have shown that telomerase plays a dual role in somatic cells. Thus, if telomerase is activated before the telomere shortening reached the critical threshold (Hayflick limit), there is no chromosome fusion; in this case, telomerase acts against the accumulation of chromosomal aberrations and against genomic instability. Consequently, cells do not undergo malignant transformation processes. In contrast, if telomerase is activated when chromosomal fusion occurred and the tumor suppressor signals have been lost, then, telomerase supports cellular immortalization and carcinogenesis (Artandi and De Pihno, 2000). 


\section{Telomeropathies and aging-associated diseases}

The length of telomere is correlated with cell longevity. The importance of telomere homeostasis is emphasized by the emergence of a broad spectrum of related diseases triggered by the existence of shortened telomeres, often referred to as telomeropathies, telomere disorders or telomere syndroms (Holohan et al, 2014). In telomeropathies, telomere attrition occurs as a consequence of germline mutations present in genes coding for components of telomerase and shelterin complexes or other proteins involved in telomere replication and maintenance. All these diseases share similar mutations and clinical symptoms, and are considered a single spectrum disorder (Fig. 3) (Martinez and Blasco, 2017). However, the age of onset and clinical manifestations are highly variable among affected individuals. DC, HHS, Revesz syndrome and Coats Plus syndrome are telomere disorders that manifest in childhood and are rarely found in the population. In contrast, IPF, aplastic anemia, liver cirrhosis and acute myeloid leukemia (AML) are less complicated telomere diseases that manifest in adults and are more frequent in the population (Holohan et al, 2014).

Dysfunctions in the telomere maintenance machinery have serious consequences on the stem cells compartment. In this context, telomeres of stem cells are gradually shortening at each cell division and get frayed faster than in healthy individuals, compromising the selfrenewal of tissues (Martinez and Blasco, 2017).

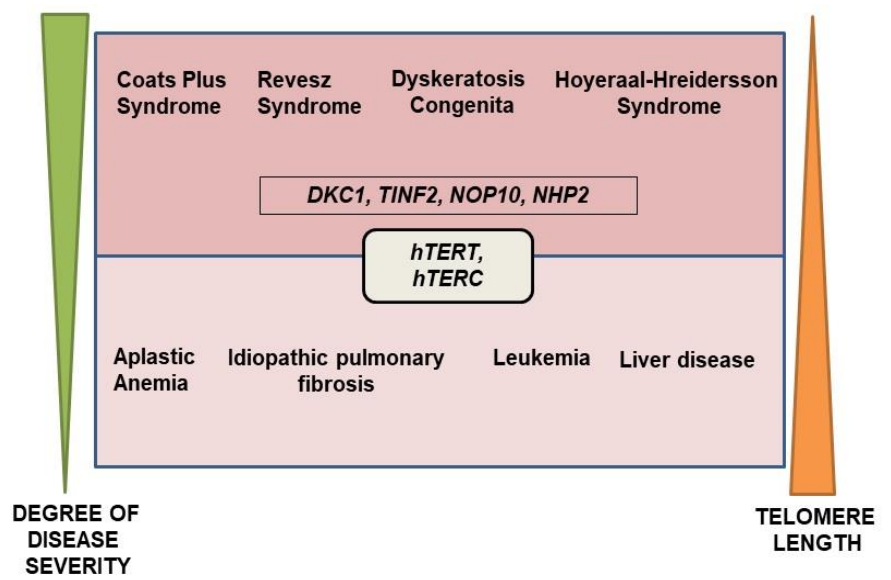

Fig. 3. Telomeropathies represent a broad spectrum of related diseases caused by mutation in telomere maintenance genes. Dyskeratosis congenita and its associated conditions are severe diseases. In telomeropathies, the presence of very short telomeres is a specific event, but DC patients display extremely short telomeres.

DC is the first disease associated with failure of the telomere maintenance machinery and causes in $80 \%$ of cases bone marrow failure and defects in hematopoiesis (Dokal, 2011). The disease begins in childhood and is characterized by extremely short telomeres. In DC, were registered mutations in 6 genes whose products are essentials to the optimal functionality of telomeres (DKC1, TERC, TERT, NOP10, NHP2 belong to the telomerase complex and TIN2 to shelterin complex) (Vulliamy and Dokal, 2008; Dokal, 2011). In addition, three molecular subtypes of DC were defined: X-linked recessive, autosomal dominant and autosomal recessive (Kirwan and Dokal, 2008). In accordance with this genetic heterogeneity, beyond the classical triad of associated symptoms (oral leukoplakia, nail dystrophy and skin hyperpigmentation), a plethora of new DC associated symptoms such as epiphora, cirrhosis, pulmonary disease, mental retardation, deafness, tooth loss and osteoporosis were frequently reported (Dokal, 2011; Kirwan and Dokal, 2009). However, many studies have shown that cases of DC in which the three key symptoms do not manifest could registered (Holohan et al, 2014).

HHS, a severe form of DC, is a multisystem genetic disorder characterized by bone marrow failure, severe growth retardation, immunodeficiency, microcephaly and cerebellar hypoplasia (Berthet et al.,1994; Aalfs et al, 1995). Previous studies have revealed that HHS can be attributed to DKC (Knight et al, 1999), TINF2 (Walne et al, 2008) gene mutations or might be caused by homozygous mutations in hTERT (Marrone et al, 2007). Moreover, a mutant form of Apollo nuclease, one of the proteins recruited to the telomeres by TRF2 and involved in the repair of DNA interstrand cross-links (ICLs), has been identified in patients with HHS (Touzot et al., 2010). Mutations in the helicase RTEL1, an enzyme that performs the T-loop release, enabling telomeric DNA replication, enrich the list of mutations commonly found in HHS (Ballew et al., 2013, Le Guen et al., 2013).

Revesz syndrome and Coats Plus syndrome are two other severe forms of DC, extremely rarely found in human population (Holohan et al, 2014). The main difference between these two disorders are that exsudative retinopathy (Kajtar and Mehes, 1994) is usually associated with Revesz syndrome, while in the Coats Plus syndrome CTC1 mutations were recurrent (Anderson et al., 2012; Polvi et al., 2012). CTC1 is a member of the CST (CTC1-STN1-TEN1) complex that is essential for telomere capping and replication (Rice and Skordalakes, 2016).

IPF is the most common condition that arise from dysfunctional telomeres and usually begins in adulthood (Armanios and Blackburn, 2012). This disease affects lung parenchyma and in most cases, the cessation of respiratory function occurs within 5 years (Lawson and Loyd, 2006). IPF is mainly determined by gene mutations that encode hTERT and hTR components of telomerase, these mutations being found in $8-15 \%$ of family cases and in a small proportion in sporadic cases (Tsakiri et al, 2007). The sporadic form of IPF can manifest even though there are no defects in telomerase core components, and extremely short telomere are a common event in these situations (Liu et al, 2013). Because 
telomere length is genetically determined, this observation draws attention to the fact that individuals with short telomere may have a higher predisposition to develop IPF.

Aplastic anemia, liver cirrhosis and AML, other telomere diseases that occur in adults are all caused by somatic or germline mutations in the genes encoding the hTERT and hTERC components of telomerase (Holohan et al, 2014). Certain patients with hTERT or hTERC mutations and bone marrow failure have experienced severe liver conditions (Calado et al, 2009), in other cases, hepatic cirrhosis may be associated with IPF and aplastic anemia (Parry et al, 2011). According to these studies, telomerase mutations can affect different organs at the same time, having important clinical implications for both patients and clinicians (Holohan et al, 2014).

Telomeropathies support the onset of other age-related diseases, such as hypertension, Alzheimer's disease, type 2 diabetes and, last but not least, cancer (Martinez and Blasco, 2017). This event might be in part explained by the fact that cells that have lost their viability accumulate in the body and release substances that disrupt tissue homeostasis (Tchkonia et al, 2013).

Another mechanism by which telomeres are involved in human diseases is TPE (Martinez and Blasco, 2017). Progressive telomere shortening enhance the expression of nearby genes that were initially repressed, and this leads to physiological dysfunctions with serious implications for the body (Doheny et al, 2008). Stadler et al. reported that gradual telomeres shortening triggered overexpression of the DUX4 gene, located near $4 \mathrm{q}$ telomere. $D U X 4$ is a gene encoding a protein involved in the pathogenesis of facioscapulohumeral muscular dystrophy (FSHD), a disorder that causes the weakness and atrophy of the scapular, facial and upper limbs muscles (Stadler et al, 2013). This study was the first to reveal a new contribution of telomeres shortening in triggering aging-related diseases.

\section{Telomeres and their involvement in carcinogenesis}

Besides the function of "molecular clock" that indicates the degree of viability and proliferation of the cell, telomeres are involved in the control of genomic integrity and play a pivotal role in initiating carcinogenesis. Although studies have focused particularly on the role of telomere shortening and activation of telomere elongation mechanisms in this process, telomere fragility, aberrant repair responses and abnormal levels of shelterins are also additional sources of genomic instability (Fig. 4). All of these issues will be discussed below.

\subsection{Somatic cells and cancer}

In most human somatic cells, the DNA replication machinery is unable to completely replicate the end of the lagging strand of telomeric DNA, and consequently, telomeres progressively shorten until reach a critical length. Without delay, a DNA damage response is launched and cells enter replicative senescence (M1). Also, this process occurs in stem cells. Cells in which DNA damage checkpoints (p53, pRB) are inactivated continue to divide beyond the senescence phase, and although their lifespan is extended, their telomeres continue to fray. These cells will enter the second state of cell cycle arrest, called crisis (M2), where the eroded ends of the chromosomes tend to fuse with each other, leading to breakage-fusion-bridge (BFB) cycles that are an important source of chromosome aberration. To prevent the generation of chromosomal instability, cells are programmed to suffer apoptosis (Wright and Shay, 1992). However, 1/10 millions cells activates TMMs to counteract the genetic chaos induced by telomere dysfunction and gain immortal proliferation capacity (Shay and Wright, 2010). In mammalian cells, two main mechanisms of TMMs have been identified. Most tumors use telomerase to expand their telomeres (Stewart et al, 2002; De Vitis et al, 2018). In contrast, in 10-20\% of tumors has been described ALT, which consists of exchange of telomeric sequences between sister chromatids (Bryan et al, 1995; Cesare and Reddel, 2010). Therefore, M1 and M2 mechanisms are two mechanisms designed to prevent genomic instability and carcinogenesis (Shay and Wright, 2010).

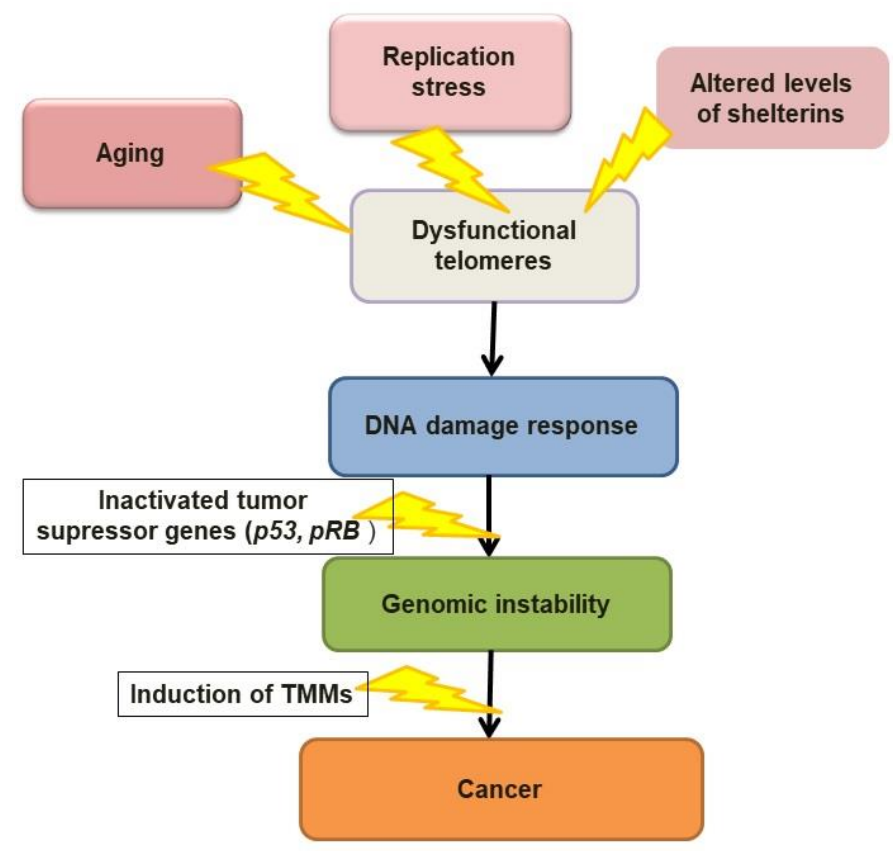

Fig. 4. Molecular mechanisms that contribute to genomic instability and carcinogenesis in somatic cells with dysfunctional telomeres.

The telomeric sequences are fragile sites, very susceptible to mutations (Sfeir et al, 2009). Due to chronic replication stress at telomeres, these fragile regions become prone to chromosomal breakage and recombination events. At the moment, oncogene activation is considered one of the most important sources of replication stress. Furthermore, replication 
stress has very important implications at the level of Gquadruplex (G4) secondary structures. G4 are stable DNA structures that are known to hinder replication fork progression, leading to DNA damage, chromosomal fusions and ultimately, to genomic instability, which is the driving force of tumorigenesis (Gunes and Rudolph, 2013; Sarni and Kerem, 2017). The presence of the shelterin complex is essential for the protection of chromosomal extremities. When telomere uncapping occurs due to the loss of shelterin proteins, eroded telomeres are recognized by cells as aberrant DNA (Sfeir and deLange, 2012; Nera et al, 2015). Consequently, DDR mechanisms are activated and perform a faulty repair of telomeric DNA. For example, it has been found that Non-homologous end joining (NHEJ) activation leads to chromosomal fusions, whereas Homology directed repair (HDR) facilitates telomeres lenghtening by ALT. Moreover, it seems that DDR pathways activated in response to loss of shelterins differs from the DDR pathways that are activated when telomeric dysfunctions are caused by other factors, but further research around this subject is needed to completely understand this selectivity (Gunes and Rudolph, 2013). Using a murine experimental model, Rai et al., concluded that the removal of the Trf2 with retrovirus-mediated shTrf2 led to chromosomal fusions induced by the classical (c-)NHEJ pathway. In the same study, where different variants of mutant mice were used, it was found that potential loss of Pot1 / Tpp1 complex may lead to alternative (alt-) NHEJ activation. These studies, consistent with others performed on murine experimental models, suggest that NHEJ is the main mechanism to process dysfunctional mice telomeres that lost shelterins during aging (Rai et al, 2010); therefore, complete understanding of this pathway and associated mechanisms in humans may provide new insights about the link between aging, genomic instability and cancer (Gunes and Rudolph, 2013).

Activation of DDR pathways also occurs as a response to telomere DNA processing and it may significantly influence the acquisition of the malignant phenotype. The 5'-3 'end resection, an event required to yield 3' singlestranded DNA (ssDNA), inhibits c-NHEJ and activates HDR, which in turn activates ALT. Resection of the 5 'DNA strand can also promote alt-NHEJ, leading to endto-end fusions (Gunes and Rudolph, 2013). Thus, additional research into DDR pathways involved in telomere processing may reveal new mechanisms that promote malignant transformation.

Altered levels of shelterins may be another source of genomic instability. As we mentioned above, the loss of shelterins causes the merger of chromosome ends, leading to $\mathrm{BFB}$ cycles that promote chromosomal instability. However, significant increased levels of shelterins are not desirable, because events can follow the same path (Nera et al, 2015). A robust body of clinical evidence revealed the presence of significant amounts of shelterins, especially TRF1, TRF2 and TIN2 in different forms of cancers. Gastric carcinomas with short telomeres expressed proeminent levels of telomerase in addition to TRF1, TRF2 and TIN2 overexpression (Matsutani et al, 2001). TRF1 and TRF2 genes, and often TIN2 gene were also found to be upregulated in adult $\mathrm{T}$ cell leukemia (Bellon et al, 2006), lung cancer (Nakanishi et al, 2003), renal cell carcinoma (RCC) (Pal et al, 2015) and hepatocarcinoma (Yokota et al, 2003). However, at the moment, the carcinogenic mechanisms triggered by telomeric binding proteins (especially TRF1 and TRF2) overexpression remain elusive. Several studies have shown that TRF1(van Steensel and de Lange T, 1997) and TRF2 overexpression result in gradual telomere shortening (Smogorzewska et al, 2000). Experimentally induced overexpression of $T R F 2$ results in replication fork stalling, subsequent formation of telomeric ultrafine anaphase bridges (UFBs), finally leading to chromosome fusions and extensive deletion of telomeric sequences. Chromosomal fusions and ruptures generated by $T R F 2$ overexpression are similar to those found in human cancers (Nera et al, 2015). Interestingly, TRF1 and TRF2 genes silencing triggered apoptosis and cell cycle arest in a RCC cell line. Thus, TRF1 and TRF2 inhibition may hold substantial promise for the attenuation of genomic instability and treatment of cancers (Pal et al, 2015).

\subsection{Stem cells and cancer}

Stem cells have the remarkable potential to diferentiate into various types of cells during early life and growth (Montagnani et al, 2016). Stem cells reside in tissues in a dynamic and specialized local microenvironment termed "niche" and have a low growth rate and longer telomeres than those of differentiated somatic cells (Ferraro et al, 2010; Shay and Wright, 2010).

Stem cells are presumed to be the origins of cancers (Gunes and Rudolph, 2013). Unlike normal somatic cells, they express low levels of telomerase, but this is not enough to prevent telomere shortening during aging (Shay and Wright, 2010). Moreover, although they have developped more efficient mechanisms of genomic integrity protection compared to normal somatic cells, stem cells are also prone to mutations. Thus, in order to alleviate the genetic chaos induced by telomere shortening and acquired mutations, cells enhance telomerase activity and become immortal (Gunes and Rudolph, 2013).

The most important clinical evidence in support of this theory comes from the study of hematopoietic cancers. AML is an agressive cancer of the bone marrow characterized by uncontrolled proliferation of hematopoietic stem cells (HSCs). Preleukemic HSCs harbor a pattern of mutations that is found recurrently in AML patients, exhibit short telomeres and elevated telomerase levels (Corces-Zimmerman et al, 2015). Thus, telomere attrition in HSCs is considered an event that contributes to the development of chromosomal instability and neoplastic transformation (Hiyama and 
Hiyama, 2007). Furthermore, telomere shortening in DC is associated with an increased risk of hematologic malignancy (Mason et al, 2005). In a similar manner to hematopoietic cancers, a plethora of human solid tumors originate from cancer stem cells (CSCs): breast, prostate, brain and melanoma (La Porta, 2012).

\section{Conclusions}

The study of telomere biology has improved significantly our knowledge regarding the functions that telomere and telomere- associated proteins exert at cellular level. Now it is well known that telomeric dysfunction is responsible for premature degeneration of tissues, induction of chromosomal aberrations and acquisition of malignant phenotype. It is desirable for this information to be further translated into clinic, but the process is difficult because it requires extensive testing and sophisticated equipment.

Telomerase gene therapy and shelterin chemical inhibitors have proved to be effective therapeutic strategies for the treatment of telomeres syndromes or aging-associated diseases, but additional studies are needed to estimate the risks and effects of long term use (Martinez and Blasco, 2017).

In cancers, therapeutic strategies are focused on targeting TMMs, considered the molecular foundations of unlimited proliferation. An arsenal of telomerase inhibitors are available, but their effectiveness is still doubtful.

In consequence, current research efforts aim to identify novel telomerase blocking agents, showing high specificity for the enzyme, low toxicity to normal cells and fewer side effects (Arndt and MacKenzie, 2016). Further complicating this scenario, tumors have the ability to switch TMMs under selective pressure of drug administration or to present both TMMs at the same time, which hampers therapeutic approaches in cancer (De Vitis et al, 2018). Therefore, additional research is needed around this topic to fully understand the molecular underpinnings of carcinogenesis and to design more effective therapies against cancer.

\section{(C)The Author(s) 2019}

Open Access This article is distributed under the terms of the Creative Commons Attribution 4.0 International License (http://creativecommons.org/licenses/by/4.0/) which permits unrestricted use, distribution, and reproduction in any medium, provided you give appropriate credit to the original author(s) and the source, provide a link to the Creative Commons license, and indicate if changes were made.

\section{References}

Aalfs C.M., van den Berg H., Barth P.G., Hennekam R.C. 1995. The Hoyeraal-Hreidarsson syndrome: the fourth case of a separate entity with prenatal growth retardation, progressive pancytopenia and cerebellar hypoplasia. Eur. J. Pediatr. 154, 304-308.

Amiard S., Doudeau M., Pinte S., Poulet A., Lenain C., Faivre-Moskalenko C., Angelov D., Hug N., Vindigni A., Bouvet P., et al. 2007. A topological mechanism for TRF2-enhanced strand invasion. Nat. Struct. Mol. Biol. 14, 147-154.

Anderson B.H., Kasher P.R., Mayer J., Szynkiewicz M., Rice G.I., Crow Y.J. 2012. Mutations in CTC1, encoding conserved telomere maintenance component 1, cause Coats plus. Nat. Genet. 44, 338-342.

Armanios M., Blackburn $\quad$ E.H. 2012. The telomere syndromes. Nat. Rev. Genet. 13, 693-704.

Arndt G.M., MacKenzie K.L. 2016. New prospects for targeting telomerase beyond the telomere. Nat. Rev. Cancer. 16, 508-524.

Artandi S.E., DePinho R.A. 2010. Telomeres and telomerase in cancer. Carcinogenesis 31, 9-18.

Ballew B. J., Joseph V., De S., Sarek G., Vannier J.-B., Stracker T., Petrini J.H.J. 2013. A Recessive founder mutation in regulator of telomere elongation helicase 1, RTEL1, underlies severe immunodeficiency and features of Hoyeraal Hreidarsson Syndrome. PLoS Genetics 9, e1003695.

Baumann P., Podell E., Cech T.R. 2002. Human POT1 (Protection of Telomeres) protein: Cytolocalization, gene structure, and alternative splicing. Mol. Cell. Biol. 22, 8079-8087.

Bellon M., Datta A., Brown M., Pouliquen J., Couppie P., Kazanji M., Nicot C. 2006. Increased expression of telomere length regulating factors TRF1, TRF2 and TIN2 in patients with adult T-cell leukemia. Int. J. Cancer. 119, 2090-2097.

Benetti R., Garcia-Cao M., Blasco M.A. 2007a. Telomere length regulates the epigenetic status of mammalian telomeres and subtelomeres. Nat. Genet. 39, 243-250.

Benetti R., Gonzalo S., Jaco I., Schotta G., Klatt P., Jenuwein T., Blasco M.A. 2007b. Suv4-20h deficiency results in telomere elongation and derepression of telomere recombination. J. Cell Biol. 178, 925-936.

Berthet F., Caduff R., Schaad U.B., Roten H., Tuchschmid P., Boltshauser E., Seger R.A. 1994. A syndrome of primary combined immunodeficiency with microcephaly, cerebellar hypoplasia, growth failure and progressive pancytopenia. Eur. J. Pediatr. 153, 333-338

Blackburn E.H., Gall J.G. 1978. A tandemly repeated sequence at the termini of the extrachromosomal ribosomal RNA genes in Tetrahymena. J. Mol. Biol. 120, 33-53.

Blasco M.A. 2007. The epigenetic regulation of mammalian telomeres. Nat. Rev. Genet. 8, 299-309.

Broccoli D., Smogorzewska A., Chong L., de Lange T. 1997. Human telomeres contain two distinct Mybrelated proteins, TRF1 and TRF2. Nat. Genet. 17, 231-235. 
Brown A.F., Podlevsky J.D., Qi X., Chen Y., Xie M., Chen J.J.L. 2014. A self-regulating template in human telomerase. Proc. Natl. Acad. Sci. USA 111, 1131111316.

Bryan T.M., Englezou A., Gupta J., Bacchetti S., Reddel R.R. 1995. Telomere elongation in immortal human cells without detectable telomerase activity. $E M B O$ J. 14, 4240-4248.

Calado R.T., Regal J.A., Kleiner D.E., Schrump D.S., Peterson N.R., Pons V., Chanock S.J., Lansdorp P.M, Young N.S. 2009. A spectrum of severe familial liver disorders associate with telomerase mutations. PLoS One. 4, e7926.

Campisi J., Kim S.H., Lim C.S., Rubio M. 2001. Cellular senescence, cancer and aging: the telomere connection. Exp. Gerontol. 36, 1619-1637.

Cesare A.J., Reddel R.R. 2010. Alternative lengthening of telomeres: Models, mechanisms and implications. Nat. Rev. Genet. 11, 319-330.

Corces-Zimmerman M.R., Hong W.J., Weissman I.L., Medeiros B.C., Majeti R. 2014. Preleukemic mutations in human acute myeloid leukemia affect epigenetic regulators and persist in remission. Proc. Natl. Acad. Sci. USA. 111, 2548-2553.

Crous-Bou M., Fung T.T., Prescott J., Julin B., Du M., Sun Q., Rexrode K. M., Hu F. B., De Vivo I. 2014. Mediterranean diet and telomere length in Nurses' Health Study: population based cohort study. BMJ. 349:g6674. doi:10.1136/bmj.g6674.

de Lange T. 2004. T-loops and the origin of telomeres. Nat. Rev. Mol. Cell. Biol. 5, 323-329.

De Vitis M., Berardinelli F., Sgura A. 2018. Telomere length maintenance in cancer: At the Crossroad between Telomerase and Alternative Lengthening of Telomeres (ALT). Int. J. Mol. Sci. 19, 606. doi:10.3390/ijms 19020606 .

Denchi E.L., de Lange T. 2007. Protection of telomeres through independent control of ATM and ATR by TRF2 and POT1. Nature 448, 1068-1071.

Doheny J. G., Mottus R., Grigliatti T. A. 2008. Telomeric position effect - a third silencing mechanism in eukaryotes. PLoS ONE. 3, e3864.

Dokal I. 2011. Dyskeratosis congenita. Hematology Am. Soc. Hematol. Educ. Program. 2011, 480-486.

Egan E.D., Collins K. 2010. Specificity and stoichiometry of subunit interactions in the human telomerase holoenzyme assembled in vivo. Mol. Cell. Biol. 30, 2775-2786.

Epel E.S., Blackburn E.H., Lin J., Dhabhar F.S., Adler N.E., Morrow J.D., Cawthon R.M. 2004. Accelerated telomere shortening in response to life stress. Proc. Natl. Acad. Sci. USA. 101, 17312-17315.

Gall J.G. 1995. Beginning of the end: origins of the telomere concept. In: Telomeres, Blackburn E.H., Greider C.W. (Ed). Cold Spring Harbor Laboratory Press, Plainview, NY, 1-10.

Garcia-Cao M., O'Sullivan R., Peters A.H., Jenuwein T., Blasco M.A. 2004. Epigenetic regulation of telomere length in mammalian cells by the Suv39h1 and Suv39h2 hist.one methyltransferases. Nat. Genet. 36, 94-99.

Gonzalo S., Jaco I., Fraga M.F., Chen T., Li E., Esteller M., Blasco M.A. 2006. DNA methyltransferases control telomere length and telomere recombination in mammalian cells. Nat. Cell. Biol. 8, 416-424.

Greider C.W., Blackburn E.H. 1985. Identification of a specific telomere terminal transferase activity in tetrahymena extracts. Cell 43, 405-413.

Gunes C., Rudolph K. L. 2013. The role of telomeres in stem cells and cancer. Cell 152, 390-393

Hanahan D., Weinberg R. 2000. The hallmarks of cancer. Cell 100, 57-70.

Harley C.B., Futcher A.B. Greider C.W. 1990. Telomeres shorten during aging. Nature 345, 458-460.

Hiyama E., Hiyama K. 2007. Telomere and telomerase in stem cells. Br. J. Cancer 96, 1020-1024.

Holohan B., Wright W.E., Shay J.W. 2014. Telomeropathies: An emerging spectrum disorder. $J$. Cell. Biol. 205, 289-299.

Huffman K.E., Levene S.D., Tesmer V.M., Shay J.W., Wright W.E. 2000. Telomere shortening is proportional to the size of the G-rich telomeric 3'overhang. J. Biol. Chem. 275, 19719-19722.

Kajtar P., Mehes K. 1994. Bilateral Coats retinopathy associated with aplastic anaemia and mild dyskeratotic signs. Am. J. Med. Genet. 49, 374-377

Kirwan M., Dokal I. 2008. Dyskeratosis congenita: a genetic disorder of many faces. Clin. Genet. 73, 10312.

Kirwan M., Dokal I. 2009. Dyskeratosis congenita, stem cells and telomeres. Biochim. Biophys. Acta. 1792, 371-379.

Knight S.W., Heiss N.S., Vulliamy T.J., Aalfs C.M., McMahon C., Richmond P., Jones A., Hennekam R.C., Poustka A., Mason P.J., Dokal I. 1999. Unexplained aplastic anaemia, immunodeficiency, and cerebellar hypoplasia (Hoyeraal-Hreidarsson syndrome) due to mutations in the dyskeratosis congenita gene, DKC1. Br. J. Haematol. 107, 335339.

La Porta C.A. 2012. Thoughts about cancer stem cells in solid tumors. World J. Stem. Cells 4, 17-20.

Lawson W.E., Loyd J.E. 2006. The genetic approach in pulmonary fibrosis: can it provide clues to this complex disease? Proc. Am. Thorac. Soc. 3, 345-349.

Le Guen T., Jullien L., Touzot F., Schertzer M., Gaillard L., Perderiset M., Carpentier W., Nitschke P., Picard C., Couillault G., et al. 2013. Human RTEL1 deficiency causes Hoyeraal-Hreidarsson syndrome with short telomeres and genome instability. Hum. Mol. Genet. 22, 3239-3249.

Lee J.Y., Jun N.R., Yoon D., Shin C., Baik I. 2015. Association between dietary patterns in the remote past and telomere length. Eur. J. Clin. Nutr. 69, 10481052. 
Leung C.W., Laraia B.A., Needham B.L., Rehkopf D.H., Adler N.E., Lin J., Blackburn E.H., Epel E.S. 2014. Soda and cell aging: associations between sugarsweetened beverage consumption and leukocyte telomere length in healthy adults from the National Health and Nutrition Examination Surveys. Am. J. Public Health 104, 2425-2431.

Li B., Oestreich S., de Lange T. 2000. Identification of human Rap1: implications for telomere evolution. Cell 101, 471-483

Liu T., Ullenbruch M., Young Choi Y., Yu H., Ding L., Xaubet A., Phan S. H. 2013. Telomerase and Telomere Length in Pulmonary Fibrosis. Am. J. Resp. Cell. Mol. Biol. 49, 260-268.

Marin C., Delgado-Lista J., Ramirez R., Carracedo J., Caballero J., Perez-Martinez P., Gutierrez-Mariscal F. M., Garcia-Rios A., Delgado-Casado N., Cruz-Teno C., Yubero-Serrano E. M., Tinahones F., Malagon M., Perez-Jimenez F., Lopez-Miranda J. 2012. Mediterranean diet reduces senescence-associated stress in endothelial cells. Age (Dordr). 34, 13091316.

Marrone A., Walne A., Tamary H., Masunari Y., Kirwan M., Beswick R., Vulliamy T., Dokal I. 2007. Telomerase reverse-transcriptase homozygous mutations in autosomal recessive dyskeratosis congenita and Hoyeraal-Hreidarsson syndrome. Blood 110, 4198-4205.

Martínez P., Blasco M.A. 2017. Telomere-driven diseases and telomere-targeting therapies. J. Cell. Biol. 216, 875-887.

Martínez P., Thanasoula M., Muñoz P., Liao C., Tejera A., McNees C., Blasco M.A. 2009. Increased telomere fragility and fusions resulting from TRF1 deficiency lead to degenerative pathologies and increased cancer in mice. Genes Dev. 23, 2060-2075.

Mason P.J., Wilson D.B., Bessler M. 2005. Dyskeratosis congenita - a disease of dysfunctional telomere maintenance. Curr. Mol. Med. 5, 159-170.

Matsutani N., Yokozaki H., Tahara E., Tahara H., Kuniyasu H., Haruma K., Chayama K., Yasui W., Tahara E. 2001. Expression of telomeric repeat binding factor 1 and 2 and TRF1-interacting nuclear protein 2 in human gastric carcinomas. Int. J. Oncol. 19, 507-512.

McKnight T.D., Shippen D.E. 2004. Plant telomere biology. Plant Cell. 16, 794-803.

Montagnani S., Rueger M.A., Hosoda T., Nurzynska D. 2016. Adult Stem Cells in Tissue Maintenance and Regeneration. Stem Cells Int. 2016, 7362879.

Nakanishi K., Kawai T., Kumaki F., Hiroi S., Mukai M. 2003. Expression of mRNAs for telomeric repeat binding factor (TRF)-1 and TRF2 in atypical adenomatous hyperplasia and adenocarcinoma of the lung. Clin. Cancer Res. 9, 1105-1111.

Nera B., Huang H.S., Lai T., Xu L. 2015. Elevated levels of TRF2 induce telomeric ultrafine anaphase bridges and rapid telomere deletions. Nat. Commun. 6, 101132.

O’Sullivan R.J., Karlseder J. 2010. Telomeres: protecting chromosomes against genome instability. Nat. Rev. Mol. Cell. Biol. 11, 171-181.

O'Connor C. 2008. Telomeres of human chromosomes. Nature Education. 1, 166.

Pal D., Sharma U., Singh S.K., Kakkar N., Prasad R. 2015. Over-expression of telomere binding factors (TRF1 \& TRF2) in renal cell carcinoma and their inhibition by using SiRNA induce apoptosis, reduce cell proliferation and migration in vitro. PLOS ONE. 10, $\mathrm{e} 0115651$.

Palm W., de Lange T. 2008. How shelterin protects mammalian telomeres. Annu. Rev. Genet. 42, 301334.

Parry E.M., Alder J.K., Qi X., Chen J.J.L., Armanios M. 2011. Syndrome complex of bone marrow failure and pulmonary fibrosis predicts germline defects in telomerase. Blood 117, 5607-5611.

Polvi A., Linnankivi T., Kivela T., Herva R., Keating J.P., Makitie O., Pareyson D., Vainionpaa L., Lahtinen J., Hovatta I. 2012. Mutations in CTC1, encoding the CTS telomere maintenance complex component 1 , cause cerebroretinal microangiopathy with calcifications and cysts. Am. J. Hum. Genet. 90, 540-549.

Raghuraman M.K., Winzeler E.A., Collingwood D., Hunt S., Wodicka L., Conway A., Lockhart D.J., Davis R.W., Brewer B.J., Fangman W.L. 2011. Replication dynamics of the yeast genome. Science 294, 115-121

Rai R., Zheng H., He H., Luo Y., Multani A., Carpenter P. B., Chang S. 2010. The function of classical and alternative non-homologous end-joining pathways in the fusion of dysfunctional telomeres. EMBO J. 29, 2598-2610.

Raynaud C.M., Sabatier L., Philipot O., Olaussen K.A., Soria J.C. 2008. Telomere length, telomeric proteins and genomic instability during the multistep carcinogenic process. Crit. Rev. Oncol. Hematol. 66, 99-117.

Rice C., Skordalakes E. 2016. Structure and function of the telomeric CST complex. Comput. Struct. Biotechnol. J. 14, 161-167.

Sarni D., Kerem B. 2017. Oncogene-Induced Replication Stress Drives Genome Instability and Tumorigenesis. Int. $\quad$ J. Mol. Sci. $\quad$ 18, 1339. doi.org/10.3390/ijms18071339.

Sfeir A. 2012. Telomeres at a glance. J. Cell. Sci. 125, 4173-4178.

Sfeir A., de Lange T. 2012. Removal of Shelterin Reveals the Telomere End-Protection Problem. Science (New York, N.Y.). 336, 593-597.

Sfeir A., Kosiyatrakul S.T., Hockemeyer D., MacRae S.L., Karlseder J., Schildkraut C.L., de Lange T. 2009. Mammalian telomeres resemble fragile sites and 
require TRF1 for efficient replication. Cell 138, 90103.

Sharpless N.E., DePinho R.A. 2007. How stem cells age and why this makes us grow old. Nat. Rev. Mol. Cell Biol. 8, 703-713.

Shay J.W. 2016. Role of telomeres and telomerase in aging and cancer. Cancer Discov. 6, 584-593.

Shay J.W., Wright W.E. 2005. Senescence and immortalization: role of telomeres and telomerase. Carcinogenesis 26, 867-874.

Shay J.W., Wright W.E. 2010. Telomeres and telomerase in normal and cancer stem cells. FEBS Letters 584 , 3819-3825.

Smogorzewska A., van Steensel B., Bianchi A., Oelmann S., Schaefer M. R., Schnapp G., de Lange T. 2000. Control of human telomere length by TRF1 and TRF2. Mol. Cell. Biol. 20, 1659-1668.

Stadler G., Rahimov F., King O.D., Chen J.C., Robin J.D., Wagner K.R., Shay J.W., Emerson C.P. Jr., Wright W.E. 2013. Telomere position effect regulates DUX4 in human facioscapulohumeral muscular dystrophy. Nat. Struct. Mol. Biol. 20, 671-678.

Stewart S.A., Hahn W.C., O’Connor B.F., Banner E.N., Lundberg A.S., Modha, P., Mizuno H., Brooks M.W., Fleming M., Zimonjic D.B. 2002. Telomerase contributes to tumorigenesis by a telomere lengthindependent mechanism. Proc. Natl. Acad. Sci. USA. 99, 12606-12611.

Takai K.K., Kibe T., Donigian J.R., Frescas D., de Lange T. 2011. Telomere protection by TPP1/POT1 requires tethering to TIN2. Mol. Cell. 44, 647-659.

Tchkonia T., Zhu Y., van Deursen J., Campisi J., Kirkland J. L. 2013. Cellular senescence and the senescent secretory phenotype: therapeutic opportunities. J. Clin. Invest. 123, 966-972.

Touzot F., Callebaut I., Soulier J., Gaillard L., Azerrad C., Durandy A., Revy P. 2010. Function of Apollo (SNM1B) at telomere highlighted by a splice variant identified in a patient with Hoyeraal-Hreidarsson syndrome. Proc. Natl. Acad. Sci. USA. 107, 1009710102.

Tsakiri K.D., Cronkhite J.T., Kuan P.J., Xing C., Raghu G., Weissler J.C., Rosenblatt R.L., Shay J.W., Garcia C.K. 2007. Adult-onset pulmonary fibrosis caused by mutations in telomerase. Proc. Natl. Acad. Sci USA. 104, 7552-7557.

Valdes A.M., Andrew T., Gardner J.P., Kimura M., Oelsner E., Cherkas L.F., Aviv A., Spector T.D. 2005. Obesity, cigarette smoking, and telomere length in women. Lancet 366, 662-664.

van Steensel B., de Lange T. 1997. Control of telomere length by human telomeric protein TRF1. Nature 385, 740-743.

Venteicher A.S., Abreu E.B., Meng Z., McCann K.E., Terns R.M., Veenstra T.D., Artandi S.E. 2009. A human telomerase holoenzyme protein required for Cajal body localization and telomere synthesis. Science (New York, N.Y.). 323, 644-648.
Venteicher A.S., Meng Z., Mason P.J., Veenstra T.D., Artandi S.E. 2008. Identification of ATPases pontin and reptin as telomerase components essential for holoenzyme assembly. Cell 132, 945-957.

Vulliamy T.J., Dokal I. 2008. Dyskeratosis congenita: the diverse clinical presentation of mutations in the telomerase complex. Biochimie 90, 122-130.

Walne A.J., Vulliamy T.J., Beswick R., Kirwan M., Dokal I. 2008. TINF2 mutations result in very short telomeres: analysis of a large cohort of patients with dyskeratosis congenita and related bone marrow failure syndromes. Blood 112, 3594-3600.

Wright W.E., Piatyszek M.A., Rainey W.E., Byrd W., Shay J.W., 1996. Telomerase activity in human germline and embryonic tissues and cells. Dev. Genet. 18, 173-179.

Wright W.E., Shay J.W. 1992. The two-stage mechanism controlling cellular senescence and immortalization. Exp. Gerontology 27, 383-389.

Yang Q., Zheng Y.L., Harris C.C. 2005. POT1 and TRF2 cooperate to maintain telomeric integrity. Mol. Cell. Biol. 25, 1070-1080.

Ye J.Z.S., Donigian J.R., Van Overbeek M., Loayza D., Luo Y., Krutchinsky A.N., Chait B.T., De Lange T. 2004. TIN2 binds TRF1 and TRF2 simultaneously and stabilizes the TRF2 complex on telomeres. $J$. Biol. Chem. 279, 47264-47271.

Yokota T., Suda T., Igarashi M., Kuroiwa T., Waguri N., Kawai H., Mita Y., Aoyagi Y. 2003. Telomere length variation and maintenance in hepatocarcinogenesis. Cancer 98, 110-118. 